\title{
SOCIOLOGIA NO ENSINO MÉDIO: ESCREVENDO CADERNOS PARA O PROJETO SÃO PAULO FAZ ESCOLA
}

\author{
Stella Christina Schrijnemaekers ${ }^{*}$ \\ Melissa de Mattos Pimenta*
}

\begin{abstract}
RESUMO: $\mathrm{O}$ artigo apresenta como se deu a elaboração e aprovação da proposta curricular para Sociologia no ensino médio, seus princípios orientadores e suas características gerais. Reflete sobre o formato idealizado pela Secretaria de Estado da Educação (SEE) para o projeto São Paulo Faz Escola, tendo em vista as limitações e as condições da rede pública em termos de recursos humanos e infraestrutura. No texto são discutidos os desafios teóricos, metodológicos, didáticos e pedagógicos de transformar a proposta em Cadernos de Sociologia para Professores e Alunos, considerando prazos, fontes de consulta, direitos autorais a que a SEE tinha acesso, entre outras adaptações necessárias. Finalmente, o texto discute os alcances e os limites da proposta, considerandose a prolongada ausência da Sociologia nos currículos escolares, a falta de professores licenciados na área e o tempo reservado à disciplina na grade curricular.
\end{abstract}

Palavras-chave: Sociologia. Ensino médio. Escola pública. Estado de São Paulo.

* Doutora em Sociologia e professora da Fundação Escola de Sociologia e Política de São Paulo (FESPSP). E-mail: stellachristina@ig.com.br

** Doutora em Sociologia e professora adjunta no Departamento de Sociologia do Instituto de Filosofia e Ciências Humanas, da Universidade Federal do Rio Grande do Sul (Ufrgs). E-mail: melissampimenta@gmail.com 
High SCHOOL Sociology:

Writing a Section for the project São Paulo Faz Escola

\begin{abstract}
The paper presents how occurred the elaboration and approval of the curriculum proposed for sociology in High School, its guiding principles and general characteristics. It reflects on the format idealized by the Department of Education (SEE) for the project São Paulo Faz Escola, in consideration of the limitations and conditions of the public, in terms of human resources and infrastructure. The text discusses the challenges theoretical, methodological, didactic and pedagogical proposal to transform books for teachers and students, considering deadlines, sources of information, copyrights that ESS had access, among other adaptations. Finally, the paper discusses the scope and limits of the proposal, considering the prolonged absence of sociology in school curricula, the lack of licensed teachers in the area and time spent on discipline in the curriculum.
\end{abstract}

Key words: Sociology. High school. Public education. State of São Paulo.

\title{
Introdução
}

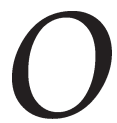

presente artigo tem por objetivo estabelecer uma reflexão sobre os desafios teóricos, metodológicos, didáticos e pedagógicos que a inserção da Sociologia no ensino médio implica, a partir do relato sobre a experiência de ter participado da confecção dos Cadernos de Sociologia para as escolas estaduais de São Paulo. ${ }^{1} \mathrm{O}$ texto procura apresentar, de forma breve, as condiçôes em que se efetivou a construção de uma proposta pedagógica para o ensino de Sociologia na educação básica em São Paulo, tendo em vista a sua reinclusão no currículo de disciplinas obrigatórias no ensino médio e a integração da proposta curricular ao projeto São Paulo Faz Escola, implementado pela Secretaria de Estado da Educação de São Paulo. Será destacado não apenas o desenho da proposta, mas a sua orientação geral em termos dos seus objetivos práticos, cuja adequação no formato dos Cadernos será colocada em discussão.

Pretende-se esclarecer como se deu o processo de criação e elaboração do material, de modo que se contribua para o debate sobre as formas de inclusão da Sociologia na educação básica. 
O retorno da disciplina de Sociologia à grade curricular obrigatória do ensino médio no Brasil e, em particular, no estado de São Paulo constitui um momento de relevância histórica, tendo em vista o tempo em que essa disciplina permaneceu excluída da grade obrigatória no país e os desafios teóricos, metodológicos, didáticos e pedagógicos que sua retomada significa.

É importante ressaltar que, ainda no século XIX, mais precisamente em 1887, ela foi considerada disciplina obrigatória nas escolas brasileiras, mas isso demorou a ser colocado em prática. Com efeito, isso só se deu em 1925, com a Reforma Rocha Vaz. Data dessa época, portanto, a introdução da Sociologia no ensino básico brasileiro. A partir de então, ela não só se tornou obrigatória no ensino secundário como também passou a integrar os vestibulares para o ingresso no ensino superior ${ }^{2}$ (Machado apud Moraes, 2003). Entretanto, ela entrou e saiu uma série de vezes da grade curricular básica nacional. Por essa razão, sua importância para a formação escolar não ficou bem estabelecida e perpetuouse o desconhecimento sobre a Sociologia pelas pessoas comuns.

O primeiro passo para superar essa situação e retomar a sua obrigatoriedade foi dado em 1996, quando foi promulgada a atual Lei de Diretrizes e Bases da Educação Nacional (LDB), Lei n. 9.394, de 20 de dezembro de 1996, que destacou a importância da Sociologia e da Filosofia como parte dos conhecimentos que os alunos devem adquirir ao longo do ensino médio. Porém, pela forma como a LDB foi escrita, a Sociologia não era vista como disciplina obrigatória, mas como parte dos conhecimentos que os jovens deveriam ter ao concluir a etapa final da educação básica - o ensino médio. A redação ambígua, que não as definia como disciplinas, mas formas de conhecimento, fez com que as Diretrizes Curriculares Nacionais do Ensino Médio (DCNEM), por meio do Parecer CNE/CEB n. 15/98 e da Resolução CNE/CEB n. 03/98, afirmassem que seus conteúdos deveriam ser abordados de forma interdisciplinar por outras matérias e assim, mais uma vez, tanto a Sociologia como a Filosofia foram excluídas do currículo obrigatório.

Somente em 2008, com a promulgação da Lei n. $11.684,{ }^{3}$ que alterou o artigo 36 da Lei n. 9.394, de 20 de dezembro de 1996, as duas disciplinas passaram a ser incluídas como explicitamente obrigatórias nos currículos de todas as séries do ensino médio. 


\section{Apresentação da proposta curricular de Sociologia}

No caso do estado de São Paulo, a proposta curricular de Sociologia que atualmente vigora é fruto de uma longa discussão de quase 30 anos, cuja origem é um texto elaborado por volta de 1983 pela Associação dos Sociólogos do Estado de São Paulo (ASESP). Ela se sustenta nas Orientaçóes Curriculares Nacionais (OCN) para o ensino de Sociologia no ensino médio.

A proposta aceita para o estado de São Paulo foi a formulada pela Sociedade Brasileira de Sociologia (SBS), por um grupo de professores e pesquisadores envolvidos com a questão do ensino de Sociologia na educação básica, atuantes em diversas universidades públicas do país. O princípio orientador geral da proposta, que concorda com a LDB em sua forma atual, é a ideia de que o ensino da Sociologia deve visar ao desenvolvimento do aluno como ser humano, por meio de uma formação ética que propicie o aprimoramento de sua autonomia intelectual e de pensamento crítico como forma de prepará-lo para a cidadania. Especificamente, ela objetiva levar "o aluno a compreender quem ele é enquanto membro da sociedade brasileira" (SEE, 2008). Neste sentido, propõe que a Sociologia propicie as condiçôes para o desenvolvimento de certa forma de pensar, denominada aqui de sensibilidade sociológica. Mas o que deve ser entendido por sensibilidade sociológica?

Uma das principais preocupaçōes tanto dos membros proponentes da SBS quanto da equipe responsável pela elaboração dos Cadernos era justamente em relação ao caráter que essa formação em Sociologia no ensino médio deveria ter. Desde o início da elaboração da proposta até o final da execução dos trabalhos estava claro que o objetivo de um ensino nesse nível não é a formação de sociólogos, mas a construção de outro olhar sobre a sociedade brasileira e sobre o lugar do aluno na sociedade em que vive, por meio de ferramentas próprias à Sociologia. Por essa razão, não haveria sentido em apenas trazer os mesmos conteúdos utilizados no ensino superior para os cursos de bacharelado em Sociologia, ou adaptá-los para o ensino médio. Tratava-se de manter o foco na interdisciplinaridade entre a Sociologia, a Antropologia e a Ciência Política, além de outras ciências humanas como a História, a Filosofia e a Geografia, que integram o currículo básico. Porém, mais importante ainda, tratava-se de manter o foco nos princípios orientadores da LDB e das OCN, cujo ponto 
de partida central é a formação e o desenvolvimento do aluno como ser humano. É, portanto, sensibilidade e não raciocínio, pois o raciocinio sociológico deve ser desenvolvido na faculdade, por aqueles que se tornarão sociólogos e estudarão a sociedade de forma científica. A sensibilidade sociológica, entretanto, constitui parte da educação básica e vem sendo defendida desde os anos de 1980 por educadores e cientistas sociais. Resta, portanto, colocá-la em prática.

Após a elaboração dos princípios norteadores e da proposta curricular, o próximo desafio era propiciar as ferramentas para que educadores e professores pudessem criar as condiçôes de desenvolvimento dessa sensibilidade em sala de aula, com os alunos da rede pública. $\mathrm{O}$ problema inicial, portanto, era transformar o texto da proposta, bem como os conteúdos ali elencados e descritos, em sugestôes de atividades práticas, adequadas ao formato exigido pela Secretaria de Estado da Educação de São Paulo.

A Sociologia tornou-se matéria obrigatória nas três séries do ensino médio. No caso do estado de São Paulo, foi introduzida concomitantemente em todas as séries a partir de 2009. Isso implicou, entre a aprovação da proposta da SBS pela SEE, o início da produção dos Cadernos e o prazo de entrega do material para o primeiro bimestre - um prazo curtíssimo para a elaboração destes. ${ }^{4}$ Todas as séries previam um Caderno para o Professor e um Caderno de Atividades para o Aluno, com base no material sugerido para o professor, para cada um dos quatro bimestres, em todas as séries, totalizando 12 Cadernos para o Professor e 12 para o aluno. Além disso, o projeto São Paulo Faz Escola previa que a equipe responsável participasse da elaboração e produção de quatro videoaulas, a serem veiculadas on-line para toda a rede estadual, por meio do portal Rede do Saber, acessado por educadores e professores da rede especificamente designados como multiplicadores do processo de formação continuada, e também de videoconferências, em tempo real, sobre os Cadernos em uso e as videoaulas veiculadas. É importante enfatizar que todo esse trabalho foi realizado pela mesma equipe, durante o período de elaboração e produção do material, e esteve sempre ancorado nos princípios orientadores da proposta curricular de Sociologia. ${ }^{5}$

Ela está dividida em torno de três grandes eixos articulados entre si. Cada um corresponde a uma série do ensino médio. Os temas 
foram sugeridos de modo a estabelecer um contato gradual entre o aluno e a Sociologia, para construir cuidadosamente, por meio da leitura e interpretação de textos, aulas dialogadas, atividades de dramatização, interpretação de imagens e outros exercícios práticos de introdução à pesquisa de campo, cujo objetivo é ajudar os alunos na compreensão do que é a Sociologia, de como se constrói um olhar sociológico sobre a realidade e de princípios e discussões norteadores que servirão para despertar e desenvolver uma sensibilidade sociológica.

Entre os principais temas desenvolvidos na $1^{\text {a }}$ série estão: o processo de desnaturalização ou estranhamento da realidade, o homem é um ser social, a socialização, relações e interações sociais na vida cotidiana, desempenho de papéis sociais, a construção social da identidade, o caráter socialmente construído da humanidade, cultura, etnocentrismo, relativismo cultural, diferença, desigualdade, raça, gênero, entre outros. Em cada bimestre há uma pergunta norteadora para o desenvolvimento da matéria e reflexão dos jovens. No primeiro bimestre da $1^{\text {a }}$ série, o aluno é levado a se questionar sobre seu lugar na sociedade e o papel da Sociologia nesse exercício. Depois, "o que lhe permite viver em sociedade" e, em seguida, no terceiro bimestre, para "o que nos une como humanos"; terminando no quarto bimestre com a questão "o que nos desiguala"?

Os recursos para desenvolver a sensibilidade sociológica são dados desde as primeiras atividades sugeridas, por meio de dois princípios: o da desnaturalização e do estranhamento. Por meio desses dois princípios procura-se fazer com que o aluno perceba, primeiramente, que o olhar da Sociologia para o objeto de sua análise se dá por meio de uma atitude de estranhamento, isto é, de afastamento e crítica ${ }^{6}$ com relação a tudo que lhe aparece como natural, como verdadeiro e definitivo. Trata-se, portanto, de construir com o aluno uma atitude ou sensibilidade que lhe permita buscar sempre uma explicação de como e por que os fenômenos sociais ocorrem, recusando sempre as explicações de sempre foram assim ou devem ser assim. Esta orientação se encontra definida nas OCN:

(...) o estranhamento. No caso da Sociologia, está em causa observar que os fenômenos sociais que rodeiam a todos e dos quais se participa não são de imediato conhecidos, pois aparecem como ordinários, triviais, corriqueiros, normais, sem necessidade de explicação, aos quais se está 
acostumada, e que na verdade nem são vistos. Assim como a chuva é um fenômeno que tem uma explicação científica, ou uma doença também tem explicações mesmo que não se tenha chegado a terapias totalmente exitosas para sua cura; ou do mesmo modo que as guerras, as mudanças de governo podem ser estudadas pela História ou os cataclismos naturais, pela Geografia; os fenômenos sociais merecem ser compreendidos ou explicados pela Sociologia. Mas só é possível tomar certos fenômenos como objeto da Sociologia na medida em que sejam submetidos a um processo de estranhamento, que sejam colocados em questão, problematizados. (Brasil, 2006, p. 106-107)

Tal posicionamento não é exclusivo à Sociologia, mas pode ser encontrado em diferentes correntes teóricas das Ciências Sociais. Tem a ver com o próprio estabelecimento da Sociologia como ciência e o desenvolvimento de seus paradigmas, de seu objeto e do método que lhe é próprio. Ela aparece em Durkheim (2005 [1895]), por exemplo, quando este afirma que "os fatos sociais devem ser tratados como coisas" (p. xvii). Ao propor esse tipo de procedimento em relação ao objeto sociológico (o fato social), Durkheim propõe uma atitude mental cuja principal dificuldade é ignorar o que se conhece previamente a respeito do que se está observando, tratando o mundo exterior como se fosse inteiramente desconhecido.

Esse mesmo exercício também é realizado na atitude proposta por Da Matta (1987, p. 157), que afirma que é preciso "tornar exótico aquilo que é familiar e tornar familiar aquilo que é exótico", a fim de se efetivamente observar aquilo o outro. ${ }^{7}$

Dessa maneira, o estranhamento é acompanhado da desnaturalização do olhar. Essa estratégia didática permite, a nosso ver, mostrar aos alunos que existem diferentes formas de conhecimento e que é a maneira específica como o sociólogo analisa a sociedade que lhe possibilita construir um conhecimento científico a seu respeito.

Estimular a adoção da postura do estranhamento é também uma forma de respeitar a heterogeneidade dos alunos. Como o estranhamento parte do conhecimento e dos saberes do aluno, a ideia é a de que o jovem construa uma sensibilidade sociológica em relação à realidade e não que sejam impostos conceitos ou pré-noções. A entrada para discutir o mundo do trabalho com um jovem já inserido no mercado de trabalho pode ser distinta daquela com um jovem que nunca trabalhou. Da mesma forma que a discussão da violência deve ocorrer 
de forma distinta entre aqueles que a vivenciam cotidianamente e os que moram em lugares com baixos índices de violência. As opiniōes e a forma de pensar a mesma questão mudam.

Dando continuidade ao exame da proposta curricular, na $2^{\text {a }}$ série também foram sugeridas atividades diversificadas, por meio do incentivo ao trabalho de leitura e interpretação de textos, incluindo trechos de autores clássicos da Sociologia, mas incluindo também a leitura e interpretação de tabelas e gráficos contendo dados sociais, econômicos e demográficos, a elaboração de textos dissertativos, a realização de entrevistas, o preenchimento e a tabulação de questionários, a análise de imagens e reportagens de jornal, entre outras atividades que propiciam ao aluno o contato com dados produzidos e utilizados por sociólogos no processo de construção do conhecimento sobre a sociedade brasileira.

Em meio aos principais temas desenvolvidos na $2^{\text {a }}$ série estão: diversidade e seu processo de formação, processos de migração e o lugar do estrangeiro na visão sociológica, cultura e cultura de massa, consumo, consumismo, trabalho como mediação, divisão social do trabalho, emprego e desemprego na atualidade e violência (contra o jovem, contra a mulher, violência escolar), entre outros. A pergunta que direciona o conteúdo do primeiro bimestre da $2^{\mathrm{a}}$ série se refere à origem da diversidade social brasileira. No segundo bimestre, a preocupação é a respeito da importância da cultura e do consumo na vida social. Já no terceiro bimestre tem a ver com a importância social do trabalho e, no quarto bimestre, o foco é a violência, seus significados e o aluno jovem em meio às situações de violência.

Finalmente, na $3^{\text {a }}$ série, o vínculo mais estreito com a Antropologia e a Sociologia dá lugar à Ciência Política, à História e à Filosofia, e as atividades sugeridas orientam-se em torno da questão da cidadania. As propostas são diversificadas e mais complexas. Envolvem não apenas a leitura e interpretação de textos clássicos, mas também de trechos da Constituição brasileira, de eventos e processos históricos, relacionando conteúdos apreendidos em outras disciplinas com os conteúdos apreendidos nas aulas de Sociologia, recurso a documentos históricos, conceitos e termos jurídicos, elaboração de textos dissertativos, debates em sala de aula, sem deixar de propiciar atividades de reflexão de maneira lúdica, com uso de imagens, letras de música, sugestão de trechos de 
filmes, entre outras. No final da $3^{a}$ série, os alunos já devem ser capazes de analisar como condições sociais diferenciadas interferem nas relações e interações entre grupos no interior de uma sociedade e de formular hipóteses explicativas para processos de reprodução de outros fenômenos sociais. Alguns temas desenvolvidos nessa série são: conceito de cidadania, direitos civis, políticos, sociais e humanos, a formação da Constituição brasileira, direitos e deveres do cidadão, formas de participação popular na história política do Brasil, movimento operário, feminista, negro, GLBTT e ambientalista, conceito de Estado, nacionalidade e soberania, organização política do Estado brasileiro, sistemas partidários, sufrágio, voto, sistemas eleitorais e eleições, estrutura e organização de um governo, o processo de desumanização e coisificação do outro, a reprodução da violência e da desigualdade social e o papel transformador da esperança e do sonho, entre outros.

A questão que norteia o primeiro bimestre da $3^{a}$ série é o significado de cidadania. No segundo bimestre, o aluno é levado a se questionar a respeito da importância da participação política. Para isso, durante o terceiro bimestre, um conjunto de informaçôes sobre a organização política do Estado brasileiro é introduzido para, finalmente, no quarto bimestre, fazer um contraponto com o que foi discutido nos bimestres anteriores, colocando em questão a ideia de cidadania formalizada nos documentos oficiais por meio da proposta de reflexão sobre o que é não cidadania, para terminar com a discussão sobre o papel do sonho e da utopia na transformação social da realidade.

Os desafios: históricos, metodológicos e didático-pedagógicos

As dificuldades encontradas na elaboração dos Cadernos podem ser agrupadas, a princípio, em três grandes grupos: históricas, metodológicas e didático-pedagógicas (Schrijnemaekers, 2009). A primeira delas deriva do modo como a Sociologia foi reintroduzida no currículo básico e do formato de sua implantação. As idas e vindas nos currículos do ensino médio tiveram efeito desastroso para a Sociologia como disciplina do ensino médio (SEB, 2006; Moraes, 2003). Ainda não há uma comunidade de professores, licenciados especificamente para lecionarem Sociologia, grande o suficiente para dar conta da rede pública 
estadual de São Paulo. Não há também uma proposta curricular aceita e testada em larga escala nos vários estados do Brasil. Com a obrigatoriedade da disciplina, um grande desafio que se coloca é o da formação de professores na área de Ciências Sociais. Hoje, o professor de Sociologia pode ser tanto um cientista social formado como um professor de Biologia que fez licenciatura em Sociologia. Sem um corpo docente envolvido com o debate, a discussão e a consolidação de um currículo básico, é mais difícil chegar a um consenso a respeito de quais saberes são importantes de serem adquiridos pelo aluno para o exercício da cidadania e da ética; pontos tão importantes quanto gerais, assinalados pela LDB.

Diante dessa realidade, a equipe de autoras orientou a elaboração dos Cadernos do Professor pensando que, nos anos iniciais de implantação da disciplina, a maior parte dos docentes responsáveis pelas aulas de Sociologia não seria formada em Ciências Sociais, como de fato não é. A dificuldade em ensinar uma disciplina à qual poucos professores tiveram acesso, quer na sua formação como educadores, quer na sua formação específica, tornava premente a necessidade de tornar os Cadernos acessíveis para qualquer profissional que viesse a ser responsável por essa disciplina. Por essa razão, os conceitos, problemas, temas e conteúdos próprios à Sociologia foram apresentados o mais gradual e claramente possível, dentro das limitações de formato e espaço impostas pela Secretaria de Estado da Educação de São Paulo e pela fundação responsável pelo processo de editoração dos Cadernos. O objetivo era apresentar a Sociologia de forma clara para alunos e professores de outras áreas, bem como convidá-los a saber mais a respeito dos diversos temas propostos, por meio de sugestões de bibliografia, fontes de consulta, pesquisas, sites na internet, entre outros recursos.

Outro ponto importante, destacado pelo próprio Ministério da Educação (Brasil, 2006), é o fato de que há poucas pesquisas que focam especificamente o ensino médio. Assim, aos escrever os Cadernos, praticamente não foi possível encontrar materiais nomeadamente orientados para o jovem matriculado nesse nível de ensino. O problema está no fato de que os textos de Sociologia utilizados no ensino superior apresentam dificuldades para os alunos nesse nível; que dirá então para um jovem de 14 ou 15 anos que ingressa no ensino médio, muitas vezes com dificuldades no desenvolvimento de competências e habilidades 
de leitura, interpretação e produção de textos escritos. Trata-se da falta de um material didático já consolidado em larga escala para o ensino médio (a maioria dos manuais destina-se ao ensino de Sociologia para o ensino superior e não é adequada ao aluno do ensino médio, seja pelo vocabulário ou pelos temas de que trata). Não há, também, praticamente, textos que discutam como determinados temas podem ser trabalhados em sala de aula. O que existe são reflexões acadêmicas sofisticadas que aparecem na Proposta Curricular, mas que devem, no mínimo, ser adaptados a esses jovens. A própria Orientação Curricular Nacional para o ensino de Sociologia apropriadamente destaca que algum tipo de adaptação deve ser feita pelo professor nas suas aulas. Isso colocou em questão tanto o uso de textos clássicos da Sociologia como a seleção dos autores, quais textos, quantos textos, bem como o tamanho dos trechos a serem utilizados nas atividades sugeridas. Em geral, a equipe optou por um meio-termo entre citaçóes originais, paráfrases de textos originais e adaptações elaboradas especialmente para o projeto a partir da pesquisa de diversas fontes bibliográficas e da consulta a diferentes autores da Sociologia. ${ }^{8}$ Entre as razões para isso está o fato de que não há consenso, dentro da própria ciência, em relação a determinados conceitos e posições metodológicas. Às vezes há autores que discordam totalmente a respeito de um determinado tema. A opção feita foi menos a de mostrar as tensões pertinentes num debate mais sofisticado - o que requer todo um conhecimento prévio de um determinado tema - e mais a de introduzir o aluno numa reflexão sobre esse tema, o que nos parece ser muito mais apropriado para um jovem que está sendo apresentado à disciplina. $\mathrm{Ou}$ seja, optou-se por desenvolver nos jovens uma sensibilidade sociológica para determinados temas e discussões mais do que os deixar a par das últimas discussões acadêmicas sobre essas problemáticas. A diversidade de correntes teóricas que fazem parte da história, da formação e do desenvolvimento da Sociologia é algo que escapa ao âmbito da proposta curricular, cabendo antes aos cursos de bacharelado. Optou-se, portanto, por deixar claro que o posicionamento da Sociologia, na qualidade de ciência, não é homogêneo, tampouco determinante em relação às razões pelas quais os fenômenos sociais se dão e à forma como eles devem ser estudados e analisados. Neste sentido, embora os Cadernos apresentem definições e conceitos, eles nunca devem ser tomados como consensuais ou pontos pacíficos, podendo inclusive ser objeto de debate e reflexão em sala de aula. 
Aliado a tudo isso, há o histórico preconceito que as Ciências Sociais sofrem no Brasil como importantes para a formação de qualquer pessoa. $\mathrm{O}$ desconhecimento favorece o surgimento de estereótipos e de preconceitos. Hoje, os professores do ensino médio terão como primeira tarefa lidar com esse preconceito enraizado em muitos jovens e nas suas famílias. ${ }^{9}$

Pode-se dizer que, historicamente, há quatro grandes dificuldades ainda a serem enfrentadas: a falta de professores capacitados para dar conta da demanda, a insuficiência de pesquisas na área de ensino, um currículo comum consensual testado e adequado para esse nível de ensino e o próprio preconceito que cerca as Ciências Sociais no Brasil. Do ponto de vista metodológico, um dos principais desafios enfrentados no retorno da Sociologia à grade curricular do ensino médio foi o fato de isso não ter sido realizado de forma gradual, ou seja, para os alunos que estavam cursando a $2^{\mathrm{a}}$ e a $3^{\mathrm{a}}$ série em 2009, o contato inicial com a Sociologia se deu nessas séries, por meio das atividades propostas para esses anos, conforme disposto na proposta acima descrita. ${ }^{10}$ Para que o processo de desenvolvimento pedagógico do programa em três anos não ficasse totalmente interrompido foi sugerido que os alunos da $2^{\mathrm{a}}$ e $3^{\mathrm{a}}$ séries tivessem contato com temas, atividades, bibliografia e conteúdos dos Cadernos da $1^{\text {a }}$ série sempre que o professor sentisse necessidade.

Os temas apresentados na proposta curricular, de acordo com o formato exigido pela SEE, foram divididos e desenvolvidos em Situações de Aprendizagem. A Situação de Aprendizagem consiste no desenvolvimento de cada tema a partir de um exercício de Sondagem e Sensibilização, durante o qual o aluno é convidado a pensar pela primeira vez a respeito do assunto a ser trabalhado nas próximas aulas. Gradualmente, são sugeridas atividades relacionadas com o tópico abordado na Sondagem e Sensibilização, até a avaliação e a proposta de recuperação. Todos os procedimentos são fundamentados nos objetivos específicos para cada aula, ou seja, em um conjunto de conhecimentos a serem trabalhados e em um conjunto de competências e habilidades que se espera que os alunos tenham desenvolvido ao final de cada Situação de Aprendizagem. Nesse formato, outro problema que logo se manifestou foi a carga horária reservada à Sociologia em cada uma das séries. Inicialmente, a $1^{\text {a }}$ e a $2^{\text {a }}$ série teriam uma aula de 50 minutos por 
semana, ao passo que a $3^{a}$ série teria duas. Posteriormente, a carga horária foi ajustada e todas as séries passaram a ter apenas uma aula por semana. Porém, o material produzido para a $3^{\text {a }}$ série foi feito para o dobro de horas-aula. Isso totaliza uma média de 8 aulas de 50 minutos por bimestre. Contudo, todo professor sabe que nunca é possível dar o número exato de minutos de uma aula, pois é preciso se deslocar de uma sala para outra, esperar os alunos acomodarem-se nas carteiras e fazer a chamada da lista de presença, entre outras açōes nesse intervalo de tempo, sem contar o tempo da discussão ou exposição do conteúdo propriamente dito. Logo, o tempo efetivo da aula é bem menor que esses já escassos 50 minutos. Com tão pouco tempo, cada aula é preciosa e o conteúdo deve ser enxuto. Um desafio enorme, portanto, era apresentar um conteúdo compacto o suficiente para caber dentro da carga horária prevista e, ao mesmo tempo, diversificado, variado, amplo e claro o suficiente para contemplar toda a proposta curricular e as demandas que a reintrodução de uma disciplina que havia ficado tanto tempo fora da grade obrigatória implicava.

Os Cadernos de Sociologia foram baseados em uma proposta aprovada pela SEE e o material produzido a partir dela não constitui, para os professores da rede pública estadual, um livro didático, e sim um conjunto de atividades sugeridas, que podem ou não ser aplicadas, a critério do professor responsável. É por essa razão que o material foi intitulado "caderno" e não "livro do professor". Mais importante ainda, os Cadernos do Aluno, por não constituírem livros didáticos, foram concebidos como cadernos de atividades, cujo objetivo é servirem de complemento às práticas pedagógicas empreendidas pelos professores e incentivarem atividades de leitura, interpretação de textos, desenvolvimento da linguagem escrita, entre outras competências e habilidades descritas nos Cadernos do Professor. Por essa razão, o conteúdo impresso nos Cadernos do Aluno é limitado às atividades, cabendo ao professor a apresentação dos conteúdos programados por meio das atividades didático-pedagógicas sugeridas.

É preciso enfatizar que, nesta perspectiva, o Caderno de Sociologia não deve servir como uma amarra ao professor, para ser aplicado de forma indiscriminada. Como qualquer outro material de natureza didático-pedagógica, necessita de adaptações, que cabem ao professor fazer de acordo com a realidade de cada uma das classes em que leciona. 
Desse modo, cabe ao educador em sala de aula, conhecedor da realidade da escola onde atua, do perfil de cada turma e dos alunos com quem convive, selecionar, adaptar, recortar, excluir e decidir quais atividades sugeridas utilizará ou não durante o curso, estabelecendo essa mediação entre os conteúdos a serem trabalhados e os alunos.

Com efeito, esse era o principal obstáculo enfrentado pela equipe de autoras na elaboração e produção dos Cadernos. Como produzir um mesmo material, a ser aplicado por toda a rede pública do estado de São Paulo, por um corpo docente tão diversificado em termos de origem, formação e tempo de experiência na área, para um corpo discente também heterogêneo, considerando as diferenças entre alunos do período diurno e noturno, da periferia, das áreas urbanas e das áreas rurais, que está entrando e saindo do mercado de trabalho, e também que nunca trabalhou antes, entre tantas outras heterogeneidades?

Outra dificuldade encontrada teve a ver com a questão dos recursos que as escolas disponibilizam aos professores no suporte às atividades didático-pedagógicas. É conhecida a grande heterogeneidade da infraestrutura da rede pública em termos de recursos como acesso a fotocópias, disponibilização de bibliotecas para professores e alunos, salas de informática, aparelhos de televisão, DVD e projeção em data show e até mesmo retroprojetores. A equipe de autoras sabia que em algumas escolas os únicos recursos disponíveis seriam lousa, giz e os Cadernos, de modo que as atividades sugeridas não poderiam incluir, por exemplo, a análise de filmes, ou qualquer outro material que demandasse a utilização desses recursos. Desse modo, todo o conteúdo para a aula precisava sempre estar disponível nos Cadernos, uma vez que as escolas apresentam recursos e capacidade muito diferentes para acessá-los.

Embora o volume mais significativo do conteúdo dos Cadernos de Sociologia para o ensino médio do estado de São Paulo esteja concentrado no Caderno do Professor, as atividades ali sugeridas têm como foco principal o aluno e, especificamente, o aluno jovem. Com base nas OCN, nos princípios norteadores da proposta curricular aprovada pela SEE e na experiência acumulada em pesquisas e no ensino de jovens, a equipe de autoras teve como principal objetivo elaborar e produzir atividades que partissem do aluno para o aluno. Porém, mais uma vez, destaca-se a dificuldade de produzir um único material para um universo muito heterogêneo. 
O aluno da rede pública é ao mesmo tempo o jovem da cidade de São Paulo, onde vivem mais de 10 milhões de habitantes, como das cidades com 10 mil habitantes ou menos. Ele pode morar na periferia, como pode pertencer aos segmentos médios e morar num bairro de camadas médias. Ele pode morar na zona urbana, na zona rural ou em cidades litorâneas. Ele pode ter o dia todo para realizar todas as tarefas, lições e pesquisa, como pode trabalhar todos os dias e só ter o domingo como dia de descanso. Pode ser ainda que ele trabalhe até no domingo. Ele pode estudar de dia ou à noite e cada uma dessas possibilidades traz especificidades que devem ser levadas em conta. Pode ter fácil acesso à internet, ou ter de caminhar quilômetros para conseguila. A violência pode estar na sua porta ou ser algo distante que ele só vê nos noticiários. Para escrever os Cadernos de Sociologia, era preciso pensar em todos esses jovens.

\section{Considerações finais}

O cerne de toda a preocupação da equipe responsável pelos Cadernos sempre foi o aluno e o que é importante para ele. Na relação de força que muitas vezes existe entre o que achamos que é importante discutir sobre um determinado assunto e o que é importante para o jovem compreender sobre esse tema, prevaleceu o que é importante para o jovem. Em outras palavras, em nossos debates internos sobre como abordar determinado assunto, a balança sempre pendeu para temas que pudessem ser relevantes para os jovens de uma forma geral.

Esse posicionamento tem origem na proposta pedagógica de Paulo Freire, que defendia uma relação distinta da tradicional hierarquia professor/aluno como sendo uma relação de transmissão de conteúdos.

Se o educador é o que sabe, se os educandos são os que nada sabem, cabe àquele dar, entregar, levar, transmitir o seu saber aos segundos. Saber que deixa de ser "experiência feita" para ser experiência narrada ou transmitida. Não é de estranhar, pois, que nesta visão "bancária" da educação, os homens sejam vistos como seres da adaptação, do ajustamento. Quanto mais se exercitem os educandos no arquivamento dos depósitos que lhes são feitos, tanto menos desenvolverão em si a consciência crítica de que resultaria sua inserção no mundo, como transformadores dele. Como sujeitos. (Freire, 2005, p. 68) 
Em todos os Cadernos, em todas as séries, a pesquisa, o diálogo e a leitura de textos são as ferramentas mais importantes de apoio ao professor. Nenhuma deve se sobrepor à outra. Infelizmente, há muitos professores que adotam a pesquisa e a leitura de textos e se esquecem do diálogo. Acham que o aluno não tem nada a acrescentar à aula, que ele vive num mundo de alienação e que cabe ao professor livrá-lo de tudo isso. Esta falta de respeito para com o jovem, seus saberes e o seu mundo é um dos fatores que contribuem para afastar muitos jovens da escola. Por essa razão, a elaboração dos Cadernos foi orientada pelo princípio de que o conhecimento deve ser construído junto com o aluno:

Assim, construindo com eles conhecimentos que tenham significância e que façam sentido em suas práticas cotidianas - um dos principais objetivos do processo de formação do raciocínio sociológico. Trabalhar os conceitos pelos conceitos, os autores pelos autores, nesse momento da formação escolar dos estudantes, pode estar bem menos propenso a atingir a finalidade de a Sociologia produzir significado na vida dos estudantes e se afirmar perante a comunidade escolar como um conhecimento fundamental para o dia a dia. (Chagas, 2009, p. 8)

Neste sentido, o formato adotado pela SEE, de um caderno contendo propostas de atividades, tem o potencial de se adequar a essa perspectiva, uma vez que possibilita autonomia ao professor e estimula, por meio de indicações de leitura, referências bibliográficas e outros recursos multimedia, o profissional da educação a se aprofundar nas temáticas e nos problemas propostos para discussão. Porém, esse processo deve ser realizado tomando-se como base sempre o aluno. Ele deve servir para a formação desse jovem como cidadão. E é isso que deve ser levado em conta como muito bem afirmou Chagas (2009). Infelizmente, há quem ache que o aluno deve aprender determinados conceitos ou autores, sem se preocupar por que é importante aprender esses conceitos e autores, e, principalmente, como tais conceitos e autores podem ajudá-lo a refletir a fim de desenvolver uma sensibilidade sociológica para refletir sobre si, a sociedade e os fenômenos sociais. O rompimento com essa visão "conteudista" é de fundamental importância para o desenvolvimento e a formação do aluno como ser humano, ou nas palavras de Freire:

É através deste [diálogo] que se opera a superação de que resulta um termo novo: não mais educador do educando, não mais educando do educador, mas educador-educando com educando-educador. Desta maneira, 
o educador já não é o que apenas educa, mas o que, enquanto educa, é educado, em diálogo com o educando que, ao ser educado, também educa. (Freire, 2005, p. 78-79)

Foi diante de todos esses desafios que os Cadernos foram elaborados. Não devem ser encarados como imposição, tampouco como um material definitivo e acabado, mas como proposta em construção, limitada e aberta a contínuo aperfeiçoamento e reformulação. De qualquer forma, esse foi um primeiro passo importantíssimo num caminho que começa a ser trilhado.

\section{Notas}

1. As autoras do presente artigo, juntamente com a professora Heloísa de Souza Martins, integraram a equipe responsável pela elaboração e pelo desenvolvimento dos Cadernos de Sociologia para Professores e Alunos das três séries do ensino médio, como parte do projeto São Paulo Faz Escola, tendo participado na produção de todos os volumes.

2. Ainda no século XIX, quando a Sociologia estava se constituindo como ciência, Rui Barbosa deu um parecer favorável sobre a disciplina e propôs sua entrada na grade curricular do curso de Direito em substituição à disciplina de Direito Natural. A relevância da disciplina, ainda que inicialmente apenas para o ensino superior, foi estabelecida concomitantemente à sua formação.

3. Disponível em: <http://www.planalto.gov.br/ccivil/_Ato2007-2010/2008/Lei/L11684. htm\#art1>. Acesso em: 19 jul. 2009.

4. A Lei n. 11.684 foi sancionada em junho de 2008 e o estado de São Paulo precisava de uma proposta curricular para o ensino de Sociologia, uma equipe para escrever os Cadernos e os alunos precisavam ter o material didático pronto no início do ano letivo de 2009. A proposta curricular foi aprovada em setembro de 2008 e a equipe foi formada em outubro daquele ano.

5. Uma equipe da Fundação Vanzolini foi responsável pela editoração dos Cadernos.

6. A crítica não deve ser entendida como julgamento negativo, mas na sua acepção científica, ou seja, a capacidade de avaliar algo e, após o exame, estabelecer uma posição própria a respeito.

7. Porém, o debate sobre a neutralidade axiológica das Ciências Sociais, que opõem positivistas e outras correntes sociológicas, coloca em questão a capacidade de efetivamente sobrepormos um olhar neutro a respeito do outro e da própria sociedade. Geertz (1978), por exemplo, afirma que nenhuma descrição é neutra, que toda descrição também é uma forma de interpretação e que o antropólogo deve ter consciência de que seu olhar não é neutro.

8. Outro problema enfrentado foi o da dificuldade de utilização de textos originais. Várias editoras não cederam os direitos autorais desses textos, o que impossibilitava a utilização de um autor por meio de suas próprias palavras.

9. As razóes para o preconceito vão desde o desconhecimento do que seja a Sociologia e para o que ela serve até o medo de que esteja ligada ao comunismo ou à doutrinação esquerdista.

Cad. Cedes, Campinas, vol. 31, n. 85, p. 405-423, set.-dez. 2011

Disponível em <http://www.cedes.unicamp.br> 
10. Essa decisão não partiu da equipe da SBS, tampouco da equipe responsável pelos Cadernos. O contrato de trabalho com as equipes previa a elaboração e produção de todo o material para as séries contempladas pelo programa, em regime seriado e bimestral, dentro dos prazos estabelecidos. Não foi aceita a proposta de utilizar o mesmo material para a $1^{\text {a }}$ série do ensino médio durante a implementação do programa para as três séries, em parte por razôes contratuais, em parte por se tratar de um material sujeito a revisão.

\section{Referências}

BRASIL. Lei n. 9.394, de 20 de dezembro de 1996. Estabelece as diretrizes e bases da educação nacional. Diário Oficial da União, Brasília, DF, 23/12/1996. Seção I, p. 27833-27841. Disponível em: <http://www.planalto.gov.br/ccivil/LEIS/L9394.htm>. Acesso em: 13 jun. 2009.

BRASIL. Lei n. 11.684, de 02 de junho de 2008. Altera o art. 36 da lei 9.394 , de 20 de dezembro de 1996, que estabelece as diretrizes e bases da educação nacional, para incluir a filosofia e a sociologia como disciplinas obrigatórias nos currículos do ensino médio. Diário Oficial da União, Brasília, DF, 03/06/2008. p. 1. Disponível em: http:// www.planalto.gov.br/ccivil/_Ato20072010/2008/Lei/L11684.htm\#art1 Acesso em: 13 jun. 2009.

BRASIL. Ministério da Educação. Secretaria da Educação Básica. Ciências humanas e suas tecnologias In: Orientaçôes curriculares para o ensino médio. Brasília, DF: MEC/SEB, 2006.

CHAGAS, S.E.A. O raciocínio sociológico como ferramenta pedagógica nas aulas de Sociologia. Revista Brasileira de História \& Ciências Sociais, São Leopoldo, v. 1, n. 2, p. 1-9, dez. 2009.

DA MATTA, R. Relativizando: uma introdução à Antropologia Social. Rio de Janeiro: Rocco, 1987.

DURKHEIM, É. As regras do método sociológico. São Paulo: Martins Fontes, 2005.

FREIRE, P. Pedagogia do oprimido. São Paulo: Paz \& Terra, 2005.

GEERTZ, C. A interpretação das culturas. Rio de Janeiro: Zahar, 1978. 
MORAES, A.C. Licenciatura em Ciências Sociais e ensino de Sociologia: entre o balanço e o relato. Tempo Social, São Paulo, v. 15, n. 1, p. 5-20, abr. 2003.

SÃO PAULO. SECRETARIA ESTADUAL DA EDUCAÇÃO. Proposta curricular do Estado de São Paulo para a disciplina de Sociologia. 2008. Disponível em: <http://www.rededosaber.sp.gov.br/contents/ SIGSCURSO/sigsc/upload/br/site_25/File/PPC_Soc_versao_ preliminar_5_nov.pdf>. Acesso em: 14 jun. 2009.

SCHRIJNEMAEKERS, S.C. O ensino de Sociologia e a escola pública: desafios. In: CONGRESSO BRASILEIRO DE SOCIOLOGIA, 14., 2009, Rio de Janeiro. Anais eletrônicos... Rio de Janeiro, 2009. Disponível em: <http://starline.dnsalias.com:8080/sbs/arquivos/ 16_6_2009_8_12_40.pdf> Acesso em: 29 jul. 2009.

Recebido em 15 de agosto de 2010

Aprovado em 22 de setembro de 2011 